Geografia e Ordenamento do Território, Revista Electrónica

Centro de Estudos de Geografia e Ordenamento do Território

http://cegot.org

CEG

Centro de Estudos de Geografia e Ordenamento do Território

ISSN: 2182-1267

Uebel, R.

Universidade Federal do Rio Grande do Sul roberto.uebel@ufrgs.br

\title{
O uso das escalas geográficas no estudo do processo de imigração contemporânea no Brasil
}

Referência: Uebel, R. (2014). O uso das escalas geográficas no estudo do processo de imigração contemporânea no Brasil. Revista de Geografia e Ordenamento do Território (GOT), n.o 5 (junho). Centro de Estudos de Geografia e Ordenamento do Território, p. 259-276

\section{Resumo}

Este artigo aborda a questão do uso das escalas geográficas como um método de estudo do processo imigratório contemporâneo no Brasil à luz dos usos do território pelos grupos imigrantes que chegaram ao Brasil desde as últimas décadas do século XX e consolidaram-se em regiões socioeconômicas estratégicas do país. Logo, o uso destas escalas permite a interpretação das relações de poder, relações políticas, sociais e econômicas que favorecem a ação e consolidação das grandes correntes migratórias não apenas no sentido sul-sul, mas também um novo fenômeno que se observa com a relação norte-sul, de imigrantes provenientes de países, como por exemplo, Haiti e Senegal e que fomenta pesquisadores da ciência geográfica a pesquisar cada vez mais sobre o tema nestas primeiras décadas do terceiro milênio.

Palavras-Chave: Imigração. Escalas. Território. Contemporaneidade. Brasil.

\section{Abstract}

This article broaches the issue of the use of geographical scales as a method of research and approach of the contemporary immigration process in Brazil in light of the usages of the territory by groups of immigrants that arrived in Brazil since the last decades of $20^{\text {th }}$ century 
and consolidated in socioeconomic strategic regions of the country. Then, the use of these scales allows the interpretation of power relations and political, social and economic relations that support the action and consolidation of great migratory flows not only toward south-south, but also in a new phenomena that is being observed in relation to north-south, of immigrants from countries as Haiti and Taiwan, for instance, and intrigues researchers from geographic science in the beginning of the new century with the possibilities and challenges from immigration.

Keywords: Immigration. Scales. Territory. Contemporaneity. Brazil.

\section{Introdução}

À luz da mundialização da sociedade e das culturas no limiar do século XXI, os processos migratórios internacionais reforçaram um novo escopo e abordagem não restritos apenas à Sociologia e à Demografia; assim, o debate sobre as grandes migrações voltou a envolver com vigor as questões econômicas, políticas e territoriais, fazendo jus então aos estudos, métodos e abordagens da Ciência Econômica e da Geografia brasileira para a interpretação do fenômeno imigratório contemporâneo. Se, no princípio do século $X X$, as correntes migratórias internacionais seguiam um padrão Norte-Sul, Leste-Oeste, hoje essa situação transformou-se e há um fluxo migratório entre todas as regiões do planeta, como bem observam Rocha-Trindade (2005) e Castles e Miller (2009).

Portanto, visto que a imigração contemporânea ganhara um caráter não apenas sociológico e demográfico, mas também territorial, dentro da eminência da Ciência Geográfica, uma opção para o estudo desse processo e de seus principais atores - os imigrantes - é a abordagem das escalas geográficas de poder e gestão, dentro do método indutivo, que caracterizam um aporte metodológico que permite observar como os atores locais/regionais - localizados nos âmbitos da sociedade civil, do Estado e do mercado articulam-se entre si e com as demais escalas de poder e gestão, com vistas à promoção do desenvolvimento de territórios.

Considerar a existência de diferentes escalas atuantes em determinados territórios, possibilita a compreensão da densidade e da complexidade oriunda da multiplicidade de poderes neles existentes e atuantes. (RÜCKERT; RAMBO, 2010, p. 1). Logo, analisando-se cenários locais, por exemplo, da imigração boliviana e haitiana no Brasil - que ocorrem em estados diferentes - podemos, relacionando juntamente com as ações nas escalas nacionais 
e internacionais, partir para uma caracterização do cenário nacional da imigração contemporânea no Brasil.

Destarte, é importante ressaltar o panorama e a importância das migrações para o Brasil, país continental de vasto território e articulador de políticas públicas e de imigração ainda no século passado:

\begin{abstract}
Enquanto Furtado faz uma breve referência sobre a importância e o desenrolar inicial da imigração no território brasileiro, Caio Prado Júnior dedica um capítulo de sua obra História Econômica do Brasil e praticamente toda sua obra Formação do Brasil Contemporâneo ao tema da imigração e colonização como determinantes do desenvolvimento e formação econômica do Brasil. Além de inferir os objetivos econômicos da imigração, já apontados por Furtado, Prado Júnior resgata também os seus objetivos políticos e militares. (UEBEL, 2012, p. 46).
\end{abstract}

O território brasileiro, assim, apresentara-se sempre como um grande destino para os fluxos migratórios internacionais, por suas especificidades territoriais, sociais e econômicas de adaptação possível aos imigrantes, inferência esta observada na diversidade de grupos imigratórios que aqui se estabeleceram durante os séculos XIX e XX, como espanhóis, alemães, italianos e japoneses, e aqueles que, em prol das transformações contemporâneas do meio (sistema) técnico-científico internacional, à mercê das exigências do capitalismo, encontraram no Brasil oportunidades de prosperidade econômica e estabilidade social, como, por exemplo, sírios, haitianos, bolivianos e taiwaneses, como bem colocam Zamberlam et al. (2013) e Klein e Bacha (1989).

Novamente, a importância do uso das escalas geográficas como um meio de abordagem e estudo dessas migrações está presente quando estas se apresentam como uma ferramenta social para a interpretação das regiões e lugares, como nas palavras de Paasi:

[...] how current interpretations of scale as social construct contribute to and challenge the interpretations of region and place, thus hopefully complementing the recent profound reviews of the notion of scale. (PAASI, 2004, p. 1). 
É importante ressaltar ainda que as escalas geográficas apresentam-se bem delimitadas quando de uma análise dos processos migratórios contemporâneos, que para esta pesquisa poderiam ser assim definidas: escala global, escala nacional, escala estadual e escala local. Tal delimitação será importante para as futuras arguições de resultados encontrados com a pesquisa, conforme demonstra Cargnin (2011):

[...] a análise do comportamento dos atores que atuam sobre um determinado território, nas principais escalas de poder e gestão, permite que se observem elementos de como esses agentes se articulam com vistas à promoção do desenvolvimento regional. (CARGNIN, 2011, p. 223).

\section{Escalas, imigração e território: a pesquisa}

A presente pesquisa não possui como foco principal o desenvolvimento regional; todavia, a mesma acepção acima permite o concomitante estudo e arguição das imigrações contemporâneas no Brasil, já que, ainda segundo Paasi, a escala geográfica é uma epistemologia, uma forma de conhecer o mundo (PAASI, 2004). Logo, utilizando-se os instrumentais da escala geográfica, é possível estabelecermos um parâmetro de análise e conclusões a respeito de resultados antes não possíveis de visualização com as escalas cartográficas, sempre dentro do método indutivo, isto é, partindo-se da análise dos cenários regionais de grupos imigratórios para a construção de uma imagem do cenário nacional total. Portanto, a adoção das escalas como estratégia de apreensão da realidade e escolha de diferentes espaços de conceptualização implica não privilegiar apenas um nível de análise (RÜCKERT, s.d.).

O referencial teórico de uma pesquisa que pretende investigar temáticas entrelaçadas de imigração, escalas geográficas e espaço social, está diretamente ligado à própria produção científica da ciência geográfica contemporânea e os conceitos oriundos desta, como por exemplo, território, espaço social e homem social, desenvolvidos por autores como Raffestin (1987), que na sua definição de território e territorialidade, permitirá vislumbrarmos o cenário da imigração no Brasil, por exemplo:

“Un territoire est ainsi produit autour de la ville et tout un système de relations est mis en place, systèmes, justement, qui définit la territorialité, pas tout la 
territorialité caractère systémique des transformations. La territorialité est exprimée dans ce cas par l'évolution des phases d'un double cycle." (RAFFESTIN, 1987, p. 16).

Ou seja, as transformações com repercussões territoriais da imigração para o Brasil dão a tônica de importância para esta pesquisa, ao passo que o homem espacial, caracterizado neste sentido como o imigrante, faz parte deste cenário de transformação.

Além de caracterizar o imigrante como um homem espacial, sua relação é com e não sobre o espaço social: "avant les hommes étaient sensés agir sur l'espace, perçu comme étant le contenant de la relation sociale. Aujourd'hui les individus agissent avec l'espace" (LUSSAULT, 2007).

Ressalta-se ainda o caráter político-territorial dos processos migratórios, sejam estes antigos ou contemporâneos, dado que uma das principais repercussões da imigração é a ocupação do território, logo, uma forma de política territorial, quando empregada e motivada pelos agentes governamentais, fomentando novamente a interação entre as escalas globais, nacionais e regionais.

De forma clara e simples, o governo brasileiro mostrava suas intenções e preocupações com a segurança das fronteiras nacionais ao promover, com a imigração (nesse sentido colonização) espanhola na fronteira entre Rio Grande do Sul, Argentina e Uruguai, obedecendo aos parâmetros explicativos citados aqui anteriormente, o povoamento dessa estratégica região (ao delimitar um mínimo de três anos de permanência aos imigrantes, já deixava clara a intenção de um povoamento duradouro e arraigado nos locais onde se estabeleceriam).

É possível considerar o instrumento desse acordo como uma forma de política de defesa nacional com limites, intenções e consequências bem delimitadas não só ao Rio Grande do Sul, mas ao Brasil também, consoante se expôs neste trabalho de pesquisa, em ciclos específicos desde o fim do século XIX (ZAMBERLAM et al., 2013).

Nesse sentido, a questão dos policy-makers e as relações de poder para escalas específicas estão intrínsecas nesta citação de Racine, Raffestin e Ruffy: 
[...] o geógrafo, ao propor diversas representações para um conjunto dado, diversas caricaturas ou modelos, prepara em suma "planos" para as ações futuras. [...] O domínio das escalas é, portanto, prévio a toda a ação. É talvez essa a ocasião de convidar os geógrafos a descobrir uma "escala das preocupações humanas". (RACINE; RAFFESTIN; RUFFY, 1983, p. 134).

Uma das características mais marcantes da história do capitalismo tem sido a intensa mobilidade espacial da população. Dentro de cada país, as cidades transformaram-se em lócus hegemônico da acumulação de capital, acelerando o processo de urbanização, fruto não só do crescimento natural da população, mas principalmente das migrações internas oriundas do campo; como afirma Brito (1995, p. 53), "não houve economia e sociedade que se desenvolvessem sem que houvesse uma intensa mobilidade espacial da população".

Todavia, essas migrações de ordem econômica também ocorrem entre os diferentes países, o que constitui outro traço do desenvolvimento do capitalismo, dado que este se desenvolve de forma distinta entre os países. A história recente não poderia ser bem entendida se não fosse considerada a interação entre os países através das suas populações. A própria identidade de muitos deles, a sua constituição como nação, foi um produto do movimento internacional de diferentes povos.

Ainda com base no artigo de Brito (1995), observa-se que o apogeu da questão motivacional economia-migração deu-se na segunda metade do século XIX, quando as emigrações europeias tornaram-se mais relevantes. As causas estavam nas profundas mudanças pelas quais o capitalismo industrial passava, considerando-se a Segunda Revolução Industrial, um período marcado pela intensa industrialização dos países europeus e pela disputa entre eles por novos mercados consumidores e fontes de matéria-prima, originando crise econômica e instabilidade política.

Assim, ocorrendo essa mobilidade entre as diferentes escalas de análise propostas, possibilita-se encontrar quais as interferências de cada escala desde o processo de tomada de decisão de emigrar até aos efeitos dessas migrações em todas as escalas propostas, ainda em uma abordagem de consequências econômicas, sociais e territoriais. Todavia, cabe nesse quadro a necessidade de filtrar tais consequências, restringindo-nos nesta pesquisa às políticas territoriais e às repercussões territoriais (dado que o uso do termo impacto é mais 
apropriado aos estudos de longo prazo) dos processos migratórios contemporâneos no Brasil.

Para tornar mais complexo o cenário atual das migrações internacionais, ao contrário do que se observava na Segunda Revolução Industrial, os fluxos migratórios que se intensificaram estão ocorrendo no sentido da periferia para o centro do capitalismo ou dos países em desenvolvimento para os desenvolvidos, visto que as condições sociais, econômicas e demográficas dos países mais pobres estão longe de exercer a mesma atração de um século atrás (BRITO, 1995).

Coloca-se assim a seara das migrações internacionais em um contexto muito mais complexo verbi gratia as migrações sul-sul; sul-norte, norte-sul; leste-oeste; tipos de migrações muito mais diversificadas e complexas em questões sociais, economicas, políticas e identitárias de forma muito mais intensa e profícua do que as migrações dos últimos dois séculos.

O fato é que o processo migratório com motivações econômicas era e ainda é seletivo, segundo Brito (1995): uma grande parte dos imigrantes não conseguia sucesso nessa mobilidade e só restava a eles o retorno às origens ou o itinerário de milhões de migrantes migrar de cidade em cidade ou de região em região, como nômades sociais.

A professora Bilac, através da obra de Patarra (BILAC, 1995 apud PATARRA, 1995), contribui também com uma interpretação sócio-economicista dos motivos que levam ao ato de migrar. Para ela, ao lado dessas reflexões macroestruturais, as alterações na composição dos fluxos migratórios conduziram também à reformulação dos modelos baseados na ideia de sistemas migratórios centrados na análise dos vínculos que se estabelecem entre os territórios de origem e os territórios receptores, pelo fluxo e contrafluxo de pessoas, além dos vínculos econômicos e políticos. A formação de redes interpessoais e familiares entre esses territórios constitui um desses vínculos, que Portes (1995) e Massey (1990) apresentam nas bases sociológicas e econômicas do fenômeno geográfico da imigração.

Para autores como Bilac e Patarra, as alterações recentes nos fluxos migratórios e suas implicações macroeconômicas também representam a maturidade das correntes migratórias estimuladas pelas redes sociais baseadas nos laços domésticos. Assim, ligandose migrantes e não migrantes em um complexo arranjo de relações sociais e culturais, tais arranjos conduzem informação, assistência social e financeira e modelam as causas da 
migração - desde a não migração, a imigração, a migração de retorno (remigração) e a continuidade dos fluxos migratórios.

Segundo Diégues Júnior, o processo imigratório configura uma transformação do território que recebe imigrantes dos grupos nacionais não tradicionais, ou seja, não portugueses e holandeses (majoritariamente colonizadores), ocorrida essencialmente através de um meio - o trabalho -, conforme descrito pelo autor:

[...] os grupos pioneiros modificaram [a paisagem regional] com o trabalho de desbravamento e penetração; mas também sobre a paisagem cultural pela incorporação de elementos próprios, muitos dos quais se tornaram integrantes do novo quadro cultural, contribuindo assim para enriquecer, na pluralidade de aspectos que hoje apresenta, o padrão cultural luso-brasileiro. (DIÉGUES JÚNIOR, 1964, p. 109).

Convém descrever ainda outras influências materiais que os imigrantes incluíram na paisagem regional, tais como a cultura da uva, pelos italianos, e a diversificação da produção realizada pelos alemães em todo Sul do Brasil, podendo-se assim citar inúmeros eventos em que atividades imigrantes contribuíram para processos de cultivação e produção do espaço social e o território em que fizeram parte.

Contudo, no campo econômico, o desenvolvimento de um parque industrial baseado no progresso normal do trabalho do artesanato se apresenta como a mais expressiva contribuição do imigrante (DIÉGUES JÚNIOR, 1964). Os artesãos europeus tiveram a oportunidade de converter suas oficinas em estabelecimentos industriais. Grandes fábricas hoje, em diferentes setores da indústria, tiveram sua origem no artesanato rural.

Assinala-se assim o imigrante estrangeiro chegado ao Brasil como o responsável pela inclusão de uma série de elementos culturais novos que se difundiram e se incorporaram aos elementos nacionais. Não se trata somente de uma transcendência sociológica, mas também de especificidades culturais, costumes, hábitos e ideias que se transmitiram entre os grupos migrantes e a sociedade brasileira já estabelecida ao longo dos últimos dois séculos, o que, conforme aponta Diégues Júnior (1964), inclui o campo econômico. 
Vale destacar, por sua repercussão particular, o papel exercido pela industrialização. Observa-se na leitura, tanto dos autores clássicos como da obra já mencionada de Diégues Júnior, verdadeiro desdobramento social da primitiva classe de colonos e de imigrantes artífices, que passavam de categoria, se transferindo do primitivo ambiente rural - onde se estabeleceram as primeiras concentrações de colonos e imigrantes em território sulbrasileiro - para as vilas criadas recentemente, ou acompanhavam o desenvolvimento da própria localidade. Com o crescimento das atividades industriais, surge uma classe operária nova, de que participavam os descendentes de imigrantes.

No primeiro quartel do século $X X$, à medida que a industrialização e a urbanização foram progredindo, acompanhadas por grandes afluxos de mão de obra imigrante (em sua maioria europeia e asiática), as clivagens entre ricos e pobres, a diversidade étnica e de estilos de vida acentuou-se, colidindo com as concepções do luso-brasilianismo nas terras brasileiras.

A legislação aprovada no início do século passado teve como consequência a eliminação quase total dos contingentes de imigrantes provenientes do leste e do sul da Europa. A opinião pública, conforme demonstra Rocha-Trindade (1995), respondeu ambivalentemente aos efeitos das vagas migratórias, reconciliando esses sentimentos anti-imigratórios, tendo por referente os mitos do progresso e a crença no poder da sociedade nacional em transformar os estrangeiros.

Nessa acepção, aliada ao nacionalismo imposto pela ditadura getulista, os imigrantes (agora já em sua segunda e terceira geração de descendentes nascidos no Brasil) deveriam adotar valores e comportamentos conformes aos padrões da cultura nacional. Foi nessa sequência que emergiu inicialmente nos Estados Unidos e posteriormente no Brasil a ideologia do melting-pot, estabelecendo um segundo modelo de relacionamento entre diferentes grupos étnicos e raciais.

A ideologia do melting-pot, uma metáfora que traduz a ideia de uma fusão entre diferentes grupos étnicos, começou assim por ser a resposta de uma minoria à imigração transatlântica. Para o Brasil, essa ideologia seria superior e necessária ao pensamento getulista de unidade nacional, cultural e étnica, criando uma pseudo-sociedade brasilianista na qual os imigrantes deveriam abandonar seus idiomas e costumes, a fim de formar a pátria Brasil. Enquanto filosofia, o melting-pot postulava, segundo Rocha-Trindade: 
[...] a assimilação dos diferentes grupos de imigrantes na sociedade e defendia que estes deveriam abandonar as suas características específicas em benefício de uma cultura comum resultante da amálgama de várias nacionalidades. (ROCHATRINDADE, 1995, p. 94).

Logo, no caso brasileiro, os nacionais poderiam ser de origem alemã, espanhola, francesa ou qualquer outra, porém eram, acima de tudo, o resultado da mistura elaborada a partir dos mais diversos contributos étnicos. Isso envolvia também o campo econômico até o fim da II Guerra Mundial na sociedade brasileira: o comércio deixava de ser uma especificidade de imigrantes judeus e árabes; as padarias deixavam de ser lusitanas; a partir de então tudo seria brasilianista ou, no sentido sociológico-econômico, brasileiro.

É importante mencionar que a metodologia das escalas ganha relevância em razão da multidimensionalidade do poder resultante da descentralização político-administrativa do Estado ocorrida no Brasil após os anos oitenta, período este concorrente com a retomada dos fluxos migratórios internacionais ao país. Nesse sentido, diferentes atores pertencentes ao Estado, à sociedade civil e ao mercado - em diferentes escalas -, agem sobre o território, ora estabelecendo relações conflituosas, ora sinérgicas. (RÜCKERT; RAMBO, 2010).

A escala geográfica se apresenta como uma hierarquia de níveis de análise do espaço social, que pode ser concebido, segundo Castro (1995) e Grataloup (1979), ainda como um encaixamento de estruturas. Todavia, deve-se ressaltar que sendo uma medida, a escala não é necessariamente do fenômeno, mas aquela escolhida para melhor observá-lo, dimensioná-lo e mensurá-lo, não devendo confundi-la com a dimensão do que é observado (CASTRO, 1995, p. 127).

Além de ser o artifício analítico que dá visibilidade ao real, neste caso ao perfil sócioespacial das imigrações para o Brasil, a escala de observação cria o fenômeno e aí surgem as lacunas que se pretende responder com base neste referencial teórico, principalmente da questão cíclica das imigrações no Brasil; a escala geográfica introduz o problema de multiformas do espaço, mas também ajuda a compreendê-lo, novamente das partes ao todo, sendo um jogo de relações entre fenômenos de amplitude e natureza diversas. 
Este tipo de metodologia multi-instrumental que utiliza as escalas geográficas e também a cartografia temática já se mostrara eficaz em estudos anteriores como em Cargnin (2011) e Réseau MIGREUROP (2012), o que leva-nos a propô-la também nesta pesquisa, procurando servir de um estudo de utilidade pública em futuras investigações acerca do "fenômeno" imigratório cíclico no Brasil.

Logo, a abordagem das escalas geográficas caracteriza um aporte metodológico indutivo que permite observar como os atores locais/regionais - localizados nos âmbitos da sociedade civil e do Estado - articulam-se entre si e com as demais escalas de poder e gestão, com vistas à promoção do desenvolvimento de territórios. Considerar a existência de diferentes escalas atuantes em determinados territórios, possibilita a compreensão da densidade e da complexidade oriunda da multiplicidade de poderes neles existentes e atuantes.

Ademais, o migrante, deixando sua terra, quebra sua rede originária de relações para reconstituí-la em outro lugar. É por esse motivo que, quando se desloca só ou com a família, intuitivamente busca lugares onde estejam seus compatriotas ou conhecidos. E as escalas geográficas assim novamente são úteis para ajudar na arguição dos desafios da ordem social e cultural enfrentados pelo migrante, já que, segundo Fernández e Brandão (2010), a noção de escala é um estimulante instrumento para tentar se reconectar tais dinâmicas e desafios globais com os processos localizados e regionalizados dentro desta pesquisa na imigração contemporânea ao Brasil, posto que ela possibilita realizar interpretações em rede, do local para nacional, e vice-versa.

Utilizando-se, primeiramente, da obra de Ortega e Almeida Filho (2007), verifica-se a inferência dos imigrantes como atores de um processo em que se abandona um horizonte estritamente setorial, que considera, entre outros fatores, a agricultura como o único setor de desenvolvimento das práticas imigratórias, e em que se conciliam tais atores como fundamentais no processo de desenvolvimento social do território.

Tal diversidade dos fluxos imigratórios, na personificação do imigrante, permite por meio da análise destas relações o conhecimento dos tempos/espaços do quotidiano destes e conhecer suas reivindicações. Desta forma, a territorialidade dos grupos imigrantes permite o que diz-nos Fernandes (1992): 


\footnotetext{
“Em meio próprio, contraposto ao público, o grupo manifesta a sua autonomia e a sua identidade. No espaço neutro, ao contrário, todos se podem encontrar. Não é o lugar da afirmação da identidade, a não ser quando a visibilidade simbólica do status é forte, e, por isso, nele também se tende a gerar o conflito." (FERNANDES, 1992, p. 77).
}

Não se intenciona nesta pesquisa realizar o estudo das concepções culturais e intrínsecas a cada grupo de imigrantes no Brasil nas últimas duas décadas, por exemplo, contudo, a citação acima corrobora a questão de que quando da análise regional, pontual, em uma amostra de grupos de imigrantes e da sua confrontação com as demais pontualidades imigrantes, por exemplo, senegaleses no Rio Grande do Sul, haitianos no Acre e bolivianos em São Paulo, pode-se começar a traçar cenários regionais que servirão de esteio para o panorama nacional das imigrações no Brasil. Isto quer dizer, para configurarmos o cenário total, faz-se necessário o contraposto no meio próprio, o local da imigração.

Discutir desenvolvimento territorial é realizar a assunção da conflitualidade inerente e a altercação perene de interesses múltiplos e seus variados loci de possibilidades de concentração, ou não, de projetos em disputa em variadas escalas espaciais.

A conformação de nossa estrutura social, segundo Brandão (2007), gerou uma sociedade com alto patamar de "fluidez", onde o deslocamento ocupacional, ao lado do deslocamento econômico e geográfico, obteve êxito na geração de prestígio, qualificação e renda, ou, mais especificamente, proporcionou um conjunto de expectativas de promoção individual e das famílias, levando os fluxos migratórios internacionais a tomarem a decisão de emigrar.

A modernização acelerada do capital desencadeou um processo avassalador de migração, urbanização e burocratização que rompeu os alicerces em que se erguia a vida nacional, o que remete à inferência de Brandão (2007): se enraizamento, contexto e territorialização viraram pontos decisivos das discussões acadêmicas e políticas, é porque o mundo vinha destruindo todas as permanências.

Nessa abordagem, verifica-se que os territórios não se definem por limites físicos, mas pela maneira como se produz, em seu interior, a interação social; aí reside a importância da cooperação e da partilha de conhecimentos e experiências entre atores na formação do 
ambiente territorial, tendo-se como exemplo em Abramovay (2003) o desenvolvimento diferenciado de certas regiões italianas, o que realça o papel dos atores e das organizações, entre elas o Estado brasileiro como receptor e promotor da imigração durante os séculos XIX e XX, no processo de crescimento e desenvolvimento econômico territorial.

A noção de território impede a confusão entre crescimento econômico e o processo de desenvolvimento, o que reporta diretamente ao marco teórico e problemático deste trabalho: o desenvolvimento econômico e sustentável, e não os aspectos de crescimento regional em prol de dado grupo produtivo. Trata-se de uma influência histórica embasada tanto em Ortega e Almeida Filho (2007) como em Hatton e Williamson (1998), com o objetivo não apenas de examinar como se formam e como podem ser reduzidos os custos de transação - tendo estes sido incorporados nessa ótica aos atores-imigrantes - e sim de abordá-los sob um ângulo histórico e a partir da influência que sobre eles exercem as forças sociais que os constituem, ligando-se diretamente à parte histórica da problemática deste trabalho.

A abordagem territorial do desenvolvimento estimula e instiga o estudo dos mecanismos de governança pública subjacentes à composição e à atuação dos sistemas estruturais de desenvolvimento, o que leva ao questionamento do presente trabalho, ainda que não seja sua hipótese e dialética principal, sobre as políticas públicas de promoção da imigração que ocorreram ao longo dos últimos dois séculos (MOURE, 1980).

Seguindo-se a lógica da problemática do desenvolvimento territorial como um desempenho econômico diferencial, a relação dos imigrantes com o seu meio advém como um fator de impacto desenvolvimentista por se dar como um fator intangível, referente à maneira como os atores sociais se relacionam entre si, tendo, novamente, crucial importância na explicação do processo de desenvolvimento.

As comunidades imigratórias (incluindo seus aspectos culturais) constituem um dos cinco fatores intangíveis estudados e apontados por Moure (1980) em seu projeto financiado pela União Europeia, embasado em uma pesquisa que consiste em estabelecer comparações entre distintas regiões para verificar quais fatores respondiam pelo desempenho econômico diferencial, conforme apontado anteriormente. 
Dando continuidade ao desenrolar das especificidades do desenvolvimento territorial como marco teórico, tem-se que a identidade cultural dos atores é uma característica fundamental do dito desenvolvimento: a abordagem do desenvolvimento econômico local destaca fundamentalmente os valores territoriais de identidade, diversidade e flexibilidade que existiram, no passado, nas formas de produção baseadas não apenas na grande indústria, mas em características gerais e locais de um território determinado.

Assim, o local adquiriu uma importância estratégica para se alcançar o desenvolvimento nacional. Os governos locais (escala local) estariam em condições de atrair empresas e promover sua competitividade, fornecendo, além disso, base histórico-cultural para a integração dos indivíduos-atores, isto é, os governos locais passam a gozar de uma maior capacidade de representação e legitimidade com relação a seus representados, sendo agentes institucionais de integração social e cultural de comunidades territoriais.

A ideia em voga, então, com o desenvolvimento da territorialidade e a propulsão da imigração, é inserir os territórios específicos no mercado mundial, e a construção dos espaços supranacionais vem corroborando essa tendência, a partir da qual o território emerge como uma nova unidade de referência para a atuação do Estado e a regulação de políticas públicas.

Pode-se dizer que a noção de território abre caminho para um avanço notável no estudo do próprio desenvolvimento, visto que este é resultado da forma específica como são usados os fatores materiais e imateriais disponíveis, com base nessas relações entre os atores distintos - privados, públicos e associativos - com o plano local ou regional, tendo-se ferramentas especialmente importantes para o estudo da ligação entre os territórios e as forças sociais que os compõem.

Promover o desenvolvimento territorial torna-se imperativo e árduo, pois território envolve, necessariamente, arbítrio, criação, nexo e poder, e ao substantivo "desenvolvimento" são apensados inúmeros adjetivos, conferindo a ele uma suposta multiplicidade.

O estudo dos territórios sob o ângulo das forças sociais que os compõem abre caminho para se compreender as mudanças que novas forças sociais podem imprimir à maneira como hoje se organiza o que positiva e corrobora esse estudo sobre o impacto imigratório. 
A incorporação das estratégias de desenvolvimento local nas políticas públicas federais pode representar um avanço no resgate de uma parcela importante de territórios deprimidos e propiciar a inserção desses espaços nos circuitos comerciais regionais, nacionais e internacional, o que nos leva a inquirir até que ponto a imigração pode ser determinante no desenvolvimento brasileiro, posto que as experiências internacionais já comprovassem a viabilidade dessas estratégias de desenvolvimento local.

\section{Inferências finais}

Assim, em suma, o método de abordagem escalar torna-se completamente ligado ao escopo da pesquisa em imigração contemporânea no Brasil, já que permite, dentro de cada escala, realizar as conexões propícias ao desenvolvimento, à economia e às repercussões territoriais contemporâneas da imigração, sendo de utilidade pública para a formulação de políticas imigratórias inclusive com vieses de aproveitamento territorial a posteriori.

Conforme mostra a história imigrantista brasileira, os imigrantes foram importantes para a transformação não só do espaço social urbano, em virtude da identidade cultural e social diferente, mas também contribuíram na transformação das territorialidades (ou territórios) produtivos, em especial da indústria e agricultura, na primeira metade do Século $\mathrm{XX}$, conforme exposto anteriormente.

O imigrante apresenta-se assim como um ator "misto" entre o local e o internacional, dado que atua localmente, porém, com um caráter internacional. Configura na sua ação o fator internacional como propulsor do local, ou seja, levando a imigração ou o trabalho imigrante como uma ação multiescalar do internacional agindo diretamente no local. Por exemplo, um imigrante boliviano que atua localmente numa confecção têxtil, porém, que traz consigo importantes questões de típico ator internacional: trabalho estrangeiro, direitos dos imigrantes, acordos binacionais de trabalho e imigração, violência contra estrangeiros em território brasileiro, remessas internacionais de dinheiro, tráfico internacional de pessoas e drogas, descaminho, contrabando, vantagens comparativas internacionais, divisão internacional do trabalho e uma vasta série de questões que o ator local-internacional imigrante boliviano (ou de qualquer outra nacionalidade) apresenta quando inserido no território brasileiro, sendo aí alvo da abordagem multiescalar de poder e gestão. 
Nesse sentido, podemos inferir que com as influências trazidas acima pelo ator localinternacional que caracteriza o imigrante, o desenvolvimento territorial não pode ser desconsiderado do grande impacto que a imigração causa em uma sociedade e em um território, tendo-se como grandes exemplos os Estados Unidos, onde se tenta aplicar uma rígida política imigratória principalmente nos estados do Sul, onde fronteiras foram cercadas e impactaram diretamente na economia local-regional em prol dos atores locaisinternacionais que são os imigrantes, outro exemplo é a própria União Europeia que tem seu território configurado por quistos imigratórios notáveis e influentes nas políticas do bloco econômico, dando claro exemplo a situação da Turquia, que almeja agregar-se à União Europeia e conta com expressivo número de imigrantes em países-chave do bloco, como Alemanha e França.

Outro exemplo que comprova esta hipótese da influência da imigração no desenvolvimento do território são os chineses que aportam cada vez mais em grande número no continente africano, a fim de estabelecerem bases de extração mineral e petrolífera, além de implantação de experimentos de agrotecnologia que futuramente serão replicados no país que conta com quase dois bilhões de habitantes, deste modo, a África Oriental começa a sofrer grandes mudanças com esta presença de imigrantes chineses em seu território, economia e sociedade.

Por fim, estes e outros exemplos mostram a notoriedade das ações da imigração e seus atores imigrantes que aqui definimos como atores locais-internacionais no território e seu desenvolvimento em regiões estratégicas na agenda internacional de poder e gestão, dentre elas o Brasil, que urgem a abordagem multiescalar para mapear, interpretar, compreender e quiçá tomar ações de política interna e externa ante estes novos fluxos imigratórios que caracterizam a economia, a sociedade e o território contemporâneo, com ênfase especial no Brasil.

\section{Referências Bibliográficas}

Abramovay, Ricardo. O futuro das regiões rurais. Porto Alegre: Editora UFRGS, 2003. v. 1. 149 p.

Brandão, Carlos. Territórios e Mudanças no "Padrão de Sociabilidade" no Brasil. In: ORTEGA, Antonio César. Território, Políticas Públicas e Estratégias de Desenvolvimento. Campinas: Alínea, 2007. Cap. 1, p. 17:40. 
Brito, Fausto. Os povos em movimento: as migrações internacionais no desenvolvimento do capitalismo. In: PATARRA, Neide Lopes (Coord.). Emigração e imigração internacionais no Brasil contemporâneo. 2. ed. São Paulo: Fundo de População das Nações Unidas, 1995. p. 53:66.

Cargnin, Antonio Paulo. Políticas de desenvolvimento regional no Rio Grande do Sul: vestígios, marcas e repercussões territoriais. 2011. 317f. Tese (Doutorado em Geografia) - Instituto de Geociências, Universidade Federal do Rio Grande do Sul, Porto Alegre, 2011.

Castles, Stephen; Miller, Mark J. The age of migration: international population movements in the modern world. Nova York: Guilford Press, 2009. 369 p. 4 ed.

Castro, Iná Elias de. O problema da escala. In: Castro, Iná Elias de. Geografia: conceitos e temas. Rio de Janeiro: Bertrand Brasil, 1995. p. 117-140.

Diégues Júnior, Manuel. Imigração, urbanização e industrialização: estudo sobre alguns aspectos da contribuição cultural do imigrante no Brasil. Rio de Janeiro: Centro Brasileiro de Pesquisas Educacionais, 1964. $373 \mathrm{p}$.

Fernandes, A. Teixeira. Poder local e democracia. Revista da Faculdade deLetras. v. 2. p.46-52, 1992.

Fernández, Victor Ramiro; Brandão, Carlos. Introducción. In: FERNÁNDEZ, Victor Ramiro; BRANDÃO, Carlos. Escalas y políticas del desarrollo regional: Desafíos para América Latina. 1. ed. Buenos Aires: Miño y Dávila, 2010. p. 17-43.

Grataloup, Christian. Des échelles. Espaces Temps, Paris, v. 10, n. 10-11,p.72-79, 1979. Disponível em: <http://www.persee.fr/web/revues/home/prescript/article/espat_0339-3267_1979_num_10_1_3032>. Acesso em: 28 mar. 2014.

Hatton, Timothy; Williamson, Jeffre. The age of mass migration: causes and economic impact. New York: Oxford University Press, 1998. 301 p.

Klein, Herbert; Bacha, Edmar L.. Social Change in Brazil: 1945-1985 The Incomplete Transition. Albuquerque: University of New Mexico Press, 1989.

Lussault, Michel. L'Homme spatial: La construction sociale de l'espacehumain. Paris: Seuil, 2007. 363 p.

Massey, Douglas S. The Social and Economic Origins of Immigration. Annals of the American Academy of Political and Social Science. 510. p.60-72, 1990.

Moure, Telmo. A inserção da economia imigrante na economia gaúcha. In: DACANAL, José Hildebrando et al. RS: Imigração \& Colonização. Porto Alegre: Mercado Aberto, 1980. (Série Documenta, 4). cap. 4, p. 91-113.

Ortega, Antonio César; Almeida Filho, Niemeyer. Desenvolvimento territorial, segurança alimentar e economia solidária. Campinas: Alínea, 2007. 308 p.

Paasi, Anssi. Place and region: looking through the prism of scale. Progress in Human Geography. 28(4), p.1-11, 2004.

Patarra, Neide Lopes. Emigração e imigração internacionais no Brasil contemporâneo. São Paulo: Fundo de População das Nações Unidas, 1995. 200 p.

Portes, Alejandro. Economic Sociology of Immigration, The: Essays on Networks, Ethnicity, and Entrepreneurship. Nova York: Russell Sage Foundation, 1995.

Racine, J.B.; Raffestin, C.; Ruffy, V. Escala e Ação: contribuições para uma interpretação de mecanismo de escala prática da geografia. Revista Brasileira de Geografia. 45. p.123-135, 1983.

Rocha-Trindade, Maria Beatriz. Sociologia das migrações. Lisboa: Universidade Aberta, 1995. 410 p.

Rückert, Aldomar Arnaldo; Rambo, Anelise Graciele. Metodologia das escalas geográficas de poder e gestão aplicada à análise de desenvolvimento em quatro territórios rurais no Brasil. Confins. 8. p.1-32, 2010.

Rückert, Aldomar Arnaldo. As escalas geográficas como método de procedimento. Porto Alegre, [s.d.]. Disponível em: <https://www.dropbox.com/sh/y7kgvqosalzuwk4/6n5VIhqJgj/21.\%20As\%20\%20escalas\%20geogr\%C3\%A1fica s\%20como\%20\%20m\%C3\%A9todo\%20de\%20procedimento.docx>. Acesso em: 12 jul. 2013. 
Uebel, Roberto Rodolfo Georg. Impactos da Imigração Espanhola no Desenvolvimento Econômico e Territorial do Rio Grande do Sul no Século XX. 2012. 219 f. Monografia (Bacharelado) - Curso de Ciências Econômicas, Departamento de Ciências Econômicas, Universidade Federal de Santa Maria, Santa Maria, 2013.

Zamberlam, Jurandir Et al. Imigrante: a fronteira da documentação e o difícil acesso às políticas públicas em Porto Alegre. Porto Alegre: Sólidus, 2013. 88 p. 